\title{
Mathematical optimization for planning and design of cycle paths
}

\author{
Roberto J. Liñán Ruiz ${ }^{\mathrm{a}^{*}}$, Jorge Pérez Aracil a , Victor Cabrera Cañizares ${ }^{\mathrm{b}}$ \\ ${ }^{a}$ Universidad Católica de Murcia (UCAM), \\ ${ }^{b}$ Universidad de Murcia
}

\begin{abstract}
The daily need for citizens to move for different activities, whatever its nature, has been greatly affected by the changes. The advantages resulting from the inclusion of the bicycle as a mode of transport and the proliferation of its use among citizens are numerous and extend both in the field of urban mobility and sustainable development.

Currently, there are a number of programs for the implementation, promotion or increased public participation related to cycling in cities. But ultimately, each and every one of these initiatives have the same goal, to create a mesh of effective, useful and cycling trails that allow the use of bicycles in preferred routes with high guarantees of security, incorporating bicycle model intermodal urban transport.

With the gradual implementation of bike lanes, many people have begun to use them to get around the city. But everything again needs a period of adaptation, and the reality is that the road network for these vehicles is full of obstacles to the rider. The current situation has led to the proposal that many kilometers of cycle paths needed to supply the demand of this mode of transport and, if implemented and planned are correct and sufficient.

This paper presents a mathematical programming model for optimal design of a network for cyclists is presented. Specifically, the model determines a network of bicycle infrastructure, appropriate to the characteristics of a network of existing roads.

As an application of the proposed model, the result of these experiments give a number of useful conclusions for planning and designing networks of cycle paths from a social perspective, applied to the case in the city of Malaga.
\end{abstract}




\section{Introduction}

Over recent decades the transformation and development of cities and their urban and physical characteristics, there has been a difficult pace to take on. These transformations have a common pattern of greater relevance for the inhabitants of these cities: mobility.

For some years, the streets of cities such as Málaga, comes a new element that is part of their daily lives: the bicycle. The benefits generated by the inclusion of the bicycle as a mode of transport and the proliferation of its use among citizens are innumerable and extend both in the field of urban mobility and sustainable development. The model for the implementation of a network of bike lanes is built from the design of a system of homogeneous and balanced mobility in the urban territory.

With the gradual implementation of bike lanes, many people have begun to use them to get around the city. But everything again needs a period of adaptation, and the reality is that the road network intended for these vehicles is fraught with obstacles to the rider. The current situation, led us to consider whether a city like Malaga needed more infrastructure in relation to the bike path and if it executed and planned has been correct and sufficient to supply the number of trips that occur each day in this mode of transport, understanding not only the current situation of the city, but also for the future. Based on studies by Rietveld (2004), the most important elements are to be classified as socio-cultural factors, user factors and influences from other modes of transport. You need to know the diversity of users who can use the bicycle as a mode of transport, which leads to not being able to describe a type user.

Some of the factors that have a greater impact for the use of bicycles as a mode of transport, are taken into consideration after the analysis by Rondinella (2012) where collects the results of a comprehensive study on existing international literature on the use of bicycle as one of the modes of urban transportation and insertion into the systems of urban and intercity transport, providing a summary of the factors to be taken into account when designing the actions to contribute to modal shift to cycling.

These factors can be grouped into different categories: design of intersections, street design, vehicle traffic, safety and land use, as considered in the development of Quality Index Environment bicycle Department of Public Health San Francisco.

The safety factor is one of the most important for calculating the choice of transport mode. The assessment of the safety and convenience of cyclists are affected by factors such as traffic volume (Tilahun 2007) and the proximity of infrastructure for bicycles and vehicle traffic, starring a decrease in safety and cyclist's comfort have a greater flow in vehicle traffic (Akar 2009).

Getting to measure the danger of the bicycle is somewhat complicated, because of its inherent danger and interaction with other means of transport. Methodologies have been proposed to evaluate different designs of infrastructure from the point of view of road safety of users of the bike (Carter 2006) (Natarajan 2009).

There are several studies showing the relationship between a greater number of infrastructure for cycling with the number of cyclists, that is, that after the implementation of bike lanes will increase the number of cyclists who use these infrastructures (Dill y Carrl 2003).

This is due to the possibility of increasing the perceived safety of cyclists. These studies may lead to the influence of bike lanes in suburban areas, analyzing the relationship between the use of the bike and proximity to infrastructure. The city architecture is a principal factor on the use of the bicycle (Sener2009).

A variety of studies which differ level factors arc and level path. In relation to the arc-level factors, differentiate between types of track, if I allow or not the parking lot, the type of bicycle infrastructure, pavement type, etc. Among the factors that relate to level route, highlight the travel time and the continuity of infrastructure (considered continuous if at least $75 \%$ of the route is not interrupted), the number of semaphores per round, the number of crossings route, etc. 


\section{Methodology}

The methodology described is based in the realization of the proposed design and infrastructure planning for network optimization model cyclists. The formulation is based on models that suggest minimizing an objective, conditioned by their respective constraints and their weights.

\begin{tabular}{|ll|}
\hline Nomenclature \\
$\mathrm{Z}$ & objective function \\
$\mathrm{i}, \mathrm{j}$ & network nodes \\
$\mathrm{a}_{\mathrm{i}, \mathrm{j}}$ & connected arc \\
$\mathrm{d}_{\mathrm{i}, \mathrm{j}}$ & distance of network nodes \\
$\mathrm{ca}_{\mathrm{i}, \mathrm{j}}$ & existing road width \\
$\mathrm{ac}_{\mathrm{i}, \mathrm{j}}$ & existing sidewalk width \\
$\mathrm{ap}_{\mathrm{i}, \mathrm{j}}$ & existing parking width \\
$\mathrm{CA}_{\mathrm{i}, \mathrm{j}}$ & minimum width for road \\
$\mathrm{AC}_{\mathrm{i}, \mathrm{j}}$ & minimum width for sidewalk \\
$\mathrm{AP}_{\mathrm{i}, \mathrm{j}}$ & minimum width for parking \\
$\mathrm{IMD}_{\mathrm{i}, \mathrm{j}}$ & intensity of arc \\
$\mathrm{t}_{\mathrm{cb}}$ & type of bicycle lane \\
$\mathrm{o}, \mathrm{d}$ & origin node and destination node \\
$\mathrm{d}_{\mathrm{o}, \mathrm{d}}$ & distance of origin node and destination node \\
$\mathrm{Su}_{\mathrm{i}, \mathrm{j}}$ & user security \\
$\mathrm{Pu}$ & security user profile \\
\hline
\end{tabular}

Substantiated on the calculation of minimum distances between major nodes of the areas of transport. Such as problems developed by Dijkstra's algorithm. The objective function (1) represents the minimum distance that must be designed cycling network, which seeks to minimize travels of different users. Previously, the minimum distance will be conditioned by the different variables that affect safety, directly from the characteristics of the road network characteristics and on the other hand, the safety profiles estimated.

$$
\min Z=\sum_{o, d \in[1, \cdots, N]} d_{o, d}
$$

There are 3 restrictions at the infrastructure level. The checks made are for sidewalks, road and parking for each of the arcs that are modeled network. As indicated by equation 2, is analyzed of availability sidewalk and the available width. As appears indicated in Table 1 (Characterization of the types of bike lanes Considered), are taken as minimum space for bike sidewalk and protected sidewalk bike, 4.5 and 5 meters respectively. Regarding the difference in the two sections, on the bike sidewalk is available set out in the shared use of public space without physical separation between pedestrians and cyclists. On the contrary, protected sidewalk bike is contemplated with physical separation between the space for the pedestrian and bicycle use.

$$
a c_{i, j} \geq A C_{i, j}^{\min } \in[1, \cdots, N]
$$


It is important to note the number of lanes that exists in each arc. Every arc is classified with the amount of lanes available for each direction. In arches with a rail, it's not allowed to implement the infrastructure for bike lane on the road. When there arches with 2 lanes, it will differ between one-way or two-way. The same process occurs for arcs with three or four lanes. Also the possibility of introducing the bicycle infrastructure from the intensity of traffic $\left(\mathrm{IMD}_{\mathrm{i}, \mathrm{j})}\right.$ flowing through the arc is checked, this is due to their relationship with the perception of security explained by Tilahun (2007). IMD $\mathrm{i}_{\mathrm{i}, \mathrm{j}}$ is a coefficient created from data of average intensity of vehicles, speeds and capacity of each of the arcs.

In equation 3, is calculated the number of lanes that exist in $\mathrm{a}_{\mathrm{i}, \mathrm{j}}$ and the available width is checked. In this section, for verification of minimum available space in the driveway to implement the infrastructure for differences bicycle lane 3 different types: bike lane on road runs on the road with traffic separation with a band of paint, segregated road bike is very similar to the previous one. It differs in being executed by the road with physical separation from traffic with pivots or bollards. And bikeway is a type of bike lanes running with a fully insulated to traffic infrastructure.

$$
c a_{i, j} \geq C A_{i, j}^{\min } \in[1, \cdots, N]
$$

Roadway checking results has available the result of arches that meet minimum widths for the possible implementation of the different types of bicycle lanes on the carriageway of the different arcs that make up the network.

As indicated by equation 4, availability and type of parking that has each of the arcs of the road network is analyzed. Set out a minimum width of 2.5 meters in the parking online for the possible implementation of infrastructure cycle path. And in the case of parking in battery, it has a minimum width of 5 meters.

$$
a p_{i, j} \geq A P_{i, j}^{\min } \in[1, \cdots, N]
$$

The result of these restrictions is a list of arcs with physical availability to implement some of the available types of infrastructure for the use of the bicycle.

In cases at cities applied, feature a large number of network arcs. In this methodology, is presented the solution from a network connection between the areas in which the city is divided. Each of the areas is represented by a centroid that is part of the list of nodes $(i, j)$. It forms the connection matrix between zones, represented by $d_{o, d}$. This solution is obtained by applying equation 1 .

\section{Application}

Exist many documents and plans referring to bicycle use in urban areas mention different types of bike lanes. An example of this is the description found in the Spanish DGT (Dirección General de Tráfico de España) document which distinguishes the following kinds of lanes (Traffic law 19/2001, of 19 December): bike lane, protected bike lane, bike lane on sidewalk, bike track and cyclable track.

From the DGT typologies mentioned above have been created into different kinds of lanes for the calculations made in this research as presented in Table 1. For the type of sidewalk section two alternatives are proposed. The first is designed with aim of sharing public space between the pedestrian and cycling ( 4.5 meters). The second is formed with a physical separation between the two users of the sidewalk (5 meters). 
For verification of the available space minimum in road, feature 3 different types: bike lane on road and segregated bike lane on road is very similar; the difference lies in the use of physical separation or paint. Bikeway is a type of bike lanes running on the road with a fully insulated to traffic infrastructure.

Table 1. Characterization of the types of bike lanes considered (Liñán, R. J., 2016).
\begin{tabular}{ll} 
Typology of bike lane & $\begin{array}{l}\text { Minimum width } \\
\text { (meters) }\end{array}$ \\
\hline Bike sidewalk & 4.5 \\
Protected sidewalk bike & 5 \\
Bike lane on road & 3.5 \\
Segregated bike lane on road & 3.5 \\
Bikeway & 3.5 \\
Bike lane in Parking & 2.5 / 5
\end{tabular}

First step is to check the dimensions of each of the parts that make the cross sections of the streets. The arches that do not meet the restrictions of physical space will be discarded by the algorithm for future iterations, minimizing the number of arcs getting available, thus a speed of modeling and calculation of further optimization. Subsequently, an analysis of the number of lanes available arc $\left(\mathrm{a}_{\mathrm{i}, \mathrm{j}}\right)$ available arc direction and $\operatorname{IMD}_{\mathrm{i}, \mathrm{j}}$ checking is performed. In favorable cases, the algorithm allows the arc to be part of the cycle paths network.

Table 2. Possibility of implementing the bike lanes according to the number of lanes and IMD (Liñán, R. J., 2016).

\begin{tabular}{llll}
\hline Number of lanes & Directions & $\operatorname{IMD}_{\mathrm{i}, \mathrm{j}}$ & Possibility \\
\hline 1 lane & One direction & $=1$ & ok \\
2 lanes & One direction & - & ok \\
2 lanes & Two directions & $=1$ & ok \\
3 lanes & One direction & $\leq 3$ & ok \\
3 lanes & Two directions & $\leq 2$ & ok \\
4 lanes & One direction & $\leq 3$ & ok \\
4 lanes & Two directions & $\leq 3$ & ok \\
\hline
\end{tabular}

\subsection{User security}

Safety is conditioned by the perception of each user, in studies by Harkey \{Harkey1998\}, it concludes that the most experienced cyclists often feel more comfortable when riding a bicycle that less experienced cyclists having a rating of greater comfort.

After the first analysis related to the possibility of implementing the bike lane on the street, present the relationship between the characteristics of each of the arcs and security associated to every arc: IMD $_{\mathrm{i}, \mathrm{j}}$ (intensity of arc) and $t_{c b}$ (type of bicycle lane). Thus the " $\mathrm{Su}_{\mathrm{i}, \mathrm{j}}$ " value, the result is the sum of the security of each arc $\left(\mathrm{a}_{\mathrm{ij}}\right)$, which have passed restricting physical availability is calculated previously. 


\begin{tabular}{lll} 
Table 3. Safety factor of each arc & $\left(\mathrm{IMD}_{\mathrm{i}, \mathrm{j}}\right.$ and $\left.\mathrm{t}_{\mathrm{cb}}\right)(\mathrm{Liñán}, \mathrm{R} . \mathrm{J} ., 2016)$. \\
\hline $\mathrm{Su}$ & $\mathrm{IMD}_{\mathrm{i}, \mathrm{j}}$ & Typology of bike lane \\
\hline 1 & 5 & Bike sidewalk \\
2 & 4 & Protected sidewalk bike \\
3 & 3 & Bike lane on road \\
4 & 2 & Segregated bike lane on road / Parking \\
5 & 1 & Bikeway \\
\hline
\end{tabular}

When the safety factor of each arc is greater than the minimum established, it is recognized as suitable to the arc. This restriction complies with the general principle of safety between road sections for bicycle and motorized traffic within urban areas, facilitating cycling mobility in cycle paths designed.

$$
P u \geq S u=\sum\left(I M D_{i, j}+t_{c b}\right)
$$

It is set as the minimum security value of 6 . That is, when an arc has $\mathrm{Pu} \geq 6$, this $\mathrm{a}_{\mathrm{i}, \mathrm{j}}$ shall be taken when calculating the minimum travel between major nodes, with its corresponding type of bike path $\left(\mathrm{t}_{\mathrm{cb}}\right)$. The last thing to do is calculate the minimum distances between the transport zones created for the case study. In this case, the transport zones are represented by principal nodes. Therefore, you must perform the objective function described in equation number 1 .

\section{Conclusions}

There has been a case study of the methodology presented above. The results presented below correspond to those obtained in the optimization of the network of bike lanes calculated for the city of Malaga (Spain). Of the 32 transport areas where has divided the city, there has been a analyst of connection between contiguous transport areas. A total of 54 riders that will result from the network of bike lanes Malaga get as result.

Thus they obtained the minimum distances between each of the runners planned. These results clarify the optimal route of the cycling network for the city, appropriate to their corresponding database with safety factor. The proposed solution is to find the type of bike path that must be implemented in each of the arcs, $\left(a_{i, j}\right)$, that make up the route described for each runner $\left(\mathrm{d}_{\mathrm{o}, \mathrm{d}}\right)$ of the respective transport areas.

The developed methodology proposes to minimize main objective distance to travel between different areas in the city of Malaga, conditioned by the respective own physical restrictions of road infrastructure and safety factors for the case study in question is divided. The search for the minimum distance to the design and implementation of an infrastructure of bikeways able to enjoy optimal security for more users away. 


\section{References}

Akar, G., \& Clifton, K. (2009). Influence of individual perceptions and bicycle infrastructure on decision to bike. Transportation Research Record: Journal of the Transportation Research Board, (2140), 165-172.

Carter, D. L., Hunter, W. W., Zegeer, C. V., Stewart, J. R., \& Huang, H. F. (2006). Pedestrian and bicyclist intersection safety indices: final report (No. FHWA-HRT-06-125).

Dill, J., \& Carr, T. (2003). Bicycle commuting and facilities in major US cities: if you build them, commuters will use them. Transportation Research Record: Journal of the Transportation Research Board, (1828), 116-123.

Dirección General de Tráfico (2009). Manual de recomendaciones de diseño, construcción, infraestructura, señalización, balizamiento, conservación y mantenimiento de carriles-bici. Dirección General de Tráfico, Madrid.

Liñán, R.J., Merino, S., Martínez, J. (2013). Optimization and design of bicycles lines. Proceedings of Applications of Computer Algebra (ACA, 2013), Málaga (Spain).

Liñán, R. J., Gaspar, I., Bordagaray, M., Moura, J. L., \& Ibeas, A. (2014). Optimization of Cycle Paths with Mathematical Programming. Transportation Research Procedia, 3, 848-855.

Liñán, R. J. (2016). Metodología para la optimización y diseño de las infraestructuras de carriles para bicicletas. Tesis Doctoral [en entrega].

Natarajan, S., \& Demetsky, M. J. (2009). Selection and evaluation of bicycle and pedestrian safety projects. In Transportation Research Board 88st Annual Meeting, Washington DC.

Rietveld, P., \& Daniel, V. (2004). Determinants of bicycle use: do municipal policies matter?. Transportation Research Part A: Policy and Practice, 38(7), 531-550.

Rondinella, G., Fernandez-Heredia, A., \& Monzón, A. (2012). Analysis of perceptions of utilitarian cycling by level of user experience. In Transportation Research Board 91 st Annual Meeting (No. 12-1379).

Sener, I. N., Eluru, N., \& Bhat, C. R. (2009). An analysis of bicycle route choice preferences in Texas, US. Transportation, 36(5), 511-539.

Tilahun, N. Y., Levinson, D. M., \& Krizek, K. J. (2007). Trails, lanes, or traffic: Valuing bicycle facilities with an adaptive stated preference survey.Transportation Research Part A: Policy and Practice, 41(4), 287-301. 